Article

\title{
Creep Behaviour and Microstructural Characterization of VAT 36 and VAT 32 Superalloys
}

\author{
Vagner João Gobbi ${ }^{1}$, Silvio José Gobbi ${ }^{1}$, Danieli Aparecida Pereira Reis ${ }^{2}{ }^{\circledR}$, \\ Jorge Luiz de Almeida Ferreira ${ }^{1}$, José Alexander Araújo ${ }^{1}$ and \\ Cosme Roberto Moreira da Silva ${ }^{1, *(\mathbb{D})}$ \\ 1 Faculty of Technology, University of Brasilia-UnB, Brasilia 70910-900, Brazil; \\ vagnergobbi@yahoo.com.br (V.J.G.); silviogobbi2@gmail.com (S.J.G.); jorge@unb.br (J.L.d.A.F.); \\ jaaunb@gmail.com (J.A.A.) \\ 2 Science and Technology Department, Universidade Federal de São Paulo-UNIFESP, \\ São José dos Campos 12231-280, Brazil; danielireis@gmail.com \\ * Correspondence: cosmeroberto@gmail.com; Tel.: +55-61-31071144
}

Received: 2 October 2018; Accepted: 23 October 2018; Published: 27 October 2018

check for updates

\begin{abstract}
Superalloys are used primarily for the aerospace, automotive, and petrochemical industries. These applications require materials with high creep resistance. In this work, evaluation of creep resistance and microstructural characterization were carried out at two new nickel intermediate content alloys for application in aerospace industry and in high performance valves for automotive applications (alloys VAT 32 and VAT 36). The alloys are based on a high nickel chromium austenitic matrix with dispersion of intermetallic $\mathrm{L}_{2}$ and phases containing different $(\mathrm{Nb}, \mathrm{Ti}) \mathrm{C}$ carbides. Creep tests were performed at constant load, in the temperature range of $675-750{ }^{\circ} \mathrm{C}$ and stress range of 500-600 MPa. Microstructural characterization and failure analysis of fractured surfaces of crept samples were carried out with optical and scanning electron microscopy with EDS. Phases were identified by Rietveld refinement. The results showed that the superalloy VAT 32 has higher creep resistance than the VAT 36. The superior creep resistance of the alloy VAT 32 is related to its higher fraction of carbides $(\mathrm{Nb}, \mathrm{Ti}) \mathrm{C}$ and intermetallic $\mathrm{L}_{2}$ provided by the amount of carbon, titanium, and niobium in its chemical composition and subsequent heat treatment. During creep deformation these precipitates produce anchoring effect of grain boundaries, hindering relative slide between grains and therefore inhibiting crack formation. These volume defects act also as obstacles to dislocation slip and climb, decreasing the creep rate. Failure analysis of surface fractures of crept samples showed intergranular failure mechanism at crack origin for both alloys VAT 36 and VAT 32. Intergranular fracture involves nucleation, growth, and subsequent binding of voids. The final fractured portion showed transgranular ductile failure, with dimples of different shapes, generated by the formation and coalescence of microcavities with dissimilar shape and sizes. The occurrence of a given creep mechanism depends on the test conditions. At creep tests of VAT 32 and VAT 36, for lower stresses and higher temperature, possible dislocation climb over carbides and precipitates would prevail. For higher stresses and intermediate temperatures shear mechanisms involving stacking faults presumably occur over a wide range of experimental conditions.
\end{abstract}

Keywords: creep; superalloy VAT 36; superalloy VAT 32; high temperature

\section{Introduction}

Creep is the slow and continuous deformation of a solid with time, under the influence of mechanical stresses [1-4]. Superalloys play a role in the development of jet engine technology [5-8]. Over the past 20 years, the thrust of jet engines has increased by more than $60 \%$ whereas the fuel 
consumption has fallen by $15-20 \%$, and these improvements are, in part, the result of improvements in the high-temperature properties of superalloys [9].

A variety of high-performance materials is used in modern jet engines. Aluminum and carbon-fibers composites are used in the coolest sections of engines (operating at temperatures under $\left.150^{\circ} \mathrm{C}\right)$, such as the fan and inlet casing, to reduce weight. Titanium $(\alpha+\beta$ and $\beta)$ alloys are used in engine components with operating temperatures around $550{ }^{\circ} \mathrm{C}$, which includes parts in the fan and compressor sections. Superalloys are used for components that operate above $550{ }^{\circ} \mathrm{C}$, such as the blades, discs, vanes, and other parts found in the combustion chamber and other high-temperature engine sections [10].

Materials used in the hottest engine components, such as high-pressure turbine blades and discs, must have high strength, fatigue life, fracture toughness, creep resistance, hot-corrosion resistance, and low thermal expansion properties. Nickel-based superalloys are the appropriate material for these engine components bearing in mind their capability to operate at high temperatures for long periods of time [10].

Nickel-based superalloys used in jet engines have high concentration of alloying elements (up to about $50 \%$ by weight) to provide strength, creep resistance, fatigue endurance, and corrosion resistance at high temperature. The types and concentration of alloying elements determines whether the superalloy is a solid solution-hardened or precipitation-hardened material. Precipitation-hardened superalloys are used in the hottest engine components, with their high-temperature strength and creep resistance improved by presence of $\mathrm{L}_{2}$ and other precipitates that have high thermal stability [10,11].

Iron-nickel superalloys are used in jet engines for their high-temperature properties and low thermal expansion. These superalloys, which contain 15-60\% iron and $25-45 \%$ nickel, are used in blades, discs, and engine casings that require low thermal expansion properties. Other alloying elements such as $\mathrm{Nb}, \mathrm{Mo}, \mathrm{W}, \mathrm{Ti}, \mathrm{Al}$, and $\mathrm{Cr}$ are also added deliberately to the formation of new phases with ability to support exposure to oxidizing environments at high temperatures for reasonable periods of time [11,12].

However, there is a growing interest in new superalloys with good creep resistance and low cost. For this purpose two new superalloys have been developed by Villares Metals, the VAT 36 and VAT 32 , both with intermediate nickel content but different amounts of carbon, iron, titanium, and niobium. The VAT 32 and VAT 36 poly-grained alloys can replace superalloys in turbines but its main application is for high temperature automotive valves. The VATs alloys intend to replace UNS N07751 and UNS N07080 (Nimonic 80A). These alloys are commonly applied in high temperature components such as those for automotive valves production for high performance internal combustion engines, considering its high hot strength. However, the high cost is still a problem due to the high nickel contents. The new developed alloys (VAT 32 and VAT 36) present economic advantages caused by its lower nickel content and are based on a high nickel-chromium austenitic matrix with dispersion of $\mathrm{L} 1_{2}$ phases and different carbides. In this work, these alloys were subjected to creep tests at constant load, at a temperature range of $675-750{ }^{\circ} \mathrm{C}$ and a stress range of 500-600 MPa. The creep tests were conducted in accordance with ASTM E139. The study is complemented by microstructural characterization with optical microscopy (OM), Scanning Electron Microscopy (SEM), Energy Dispersive Spectroscopy (EDS), and Rietveld refinement. The VAT 32 alloy showed higher creep resistance and these results were correlated to formation of higher amount of carbides and intermetallic phases caused by higher mass percentage of carbon and different amounts of alloying elements.

\section{Materials and Methods}

Cylindrical bars of superalloys VAT 36 and VAT 32 were provided by Villares Metals Company (Sumaré, Brazil). Specimens for creep tests were prepared with shapes and dimensions depicted in Figure 1. 


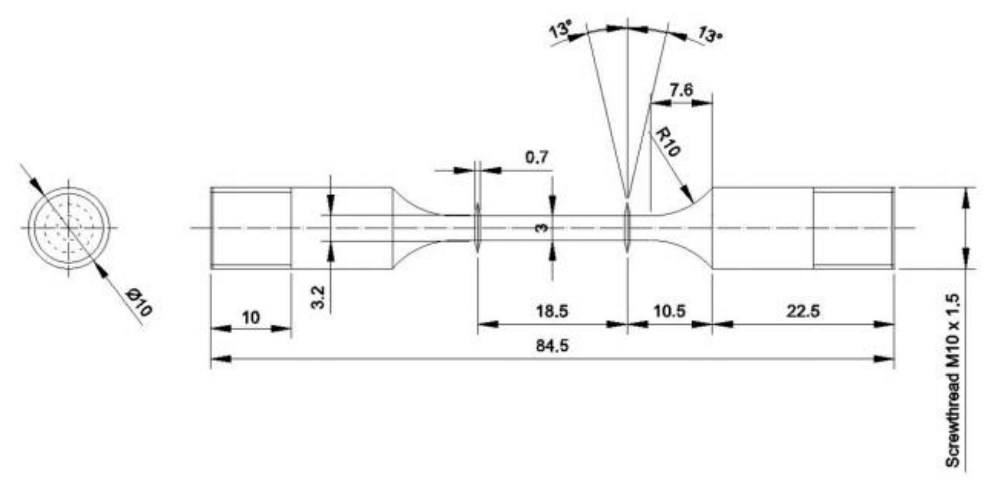

Figure 1. Dimensions of the specimen for creep tests in $\mathrm{mm}$.

The specimens were subjected to heat treatment comprising two steps: (a) solution, held at $1050^{\circ} \mathrm{C}$ during $30 \mathrm{~min}$ with a heating rate of $20^{\circ} \mathrm{C} / \mathrm{min}$, followed by air cooling; (b) aging, carried out at $750{ }^{\circ} \mathrm{C}$ during $4 \mathrm{~h}$, with a heating rate of $10^{\circ} \mathrm{C} / \mathrm{min}$ followed by air cooling. The creep tests were accomplished according to ASTM E-139-11 [13]. Electrical systems and controllers (Denison Mayes Group, Leeds, UK) were adapted in the furnace (Denison Mayes Group, Leeds, UK). A linear variable differential displacement transducer (LVDT, Denison Mayes Group, Leeds, UK) was used to obtain elongation measurements, and a Cromel-Alumel thermocouple was used for temperature control as detailed in [14]. The creep tests were performed at temperatures of 675,700 and $750{ }^{\circ} \mathrm{C}$ and in constant load mode at stresses of 500, 550, and $600 \mathrm{MPa}$. A diffractometer Philips model PW 3710 (Philips, Best, The Netherlands) was used for Rietveld refinement, operated with Cuk $\alpha$ radiation $(\lambda=1.54184 \AA$ ). The specimens were scanned at $2 \theta$ in a range of $10^{\circ} \leq 2 \theta \leq 125^{\circ}$ and step increment of $0.02^{\circ}$.

The samples preparation for analysis via Optical Microscopy (Zeiss, Jena, Germany) and Scanning Electron Microscopy (SEM) (Jeol, Tokyo, Japan) followed the standard grinding procedure using silicon carbide sandpapers. Polishing was accomplished with diamond paste Codemaq with $0.3 \mathrm{~nm}$. Etching was carried out with the kalling's reagent, with the following composition: $33 \mathrm{~mL} \mathrm{HCl}, 33 \mathrm{~mL}$ ethanol, $33 \mathrm{~mL}$ water, and $1.5 \mathrm{~g}$ of $\mathrm{CuCl}_{2}$. The scanning electron microscope was used for microstructural and energy dispersive spectroscopy (EDS) analyses. The same microscope was operated aiming to evaluate fracture surfaces of crept samples and to identify the dominant fracture mechanism in each case.

\section{Results and Discussion}

\subsection{Chemical Composition}

The chemical compositions of VAT 36 and VAT 32 alloys are shown in Table 1.

Table 1. Hemical compositions: VAT 36 and VAT 32. (Mass.\%).

\begin{tabular}{cccccccc}
\hline Alloys/Elem. & $\mathbf{N i}$ & $\mathbf{F e}$ & $\mathbf{C r}$ & $\mathbf{C}$ & $\mathbf{T i}$ & $\mathbf{N b}$ & $\mathbf{A l}$ \\
\hline VAT 36 & 35.8 & 40.21 & 18.6 & 0.05 & 1.14 & 2.0 & 1.90 \\
VAT 32 & 32.0 & 44.14 & 15.5 & 0.26 & 2.0 & 3.90 & 1.90 \\
\hline
\end{tabular}

The VAT 32 alloy has about five times more carbon and approximately two times more titanium and niobium, when compared to VAT 36. Titanium and niobium preferably combine with carbon to form carbides. The excess of titanium and niobium unreacted with carbon combines with nickel giving rise to intermetallic phases $\mathrm{L}_{2}$ and increases the creep resistance.

\subsection{Microstcuctural Evaluation after HT}

Images obtained with optical and scanning electron microscopy showed both alloys (VAT 32 and VAT 36) with heterogeneous microstructures, with twinned areas, and grains of average size of $71.83 \mu \mathrm{m}$ to 32 VAT and $70.75 \mu \mathrm{m}$ to 36 VAT. 
3.2.1. Microstructural Evaluation of Superalloy VAT 36

The microstructures for VAT 36 alloy are depicted in Figures 2 and 3.

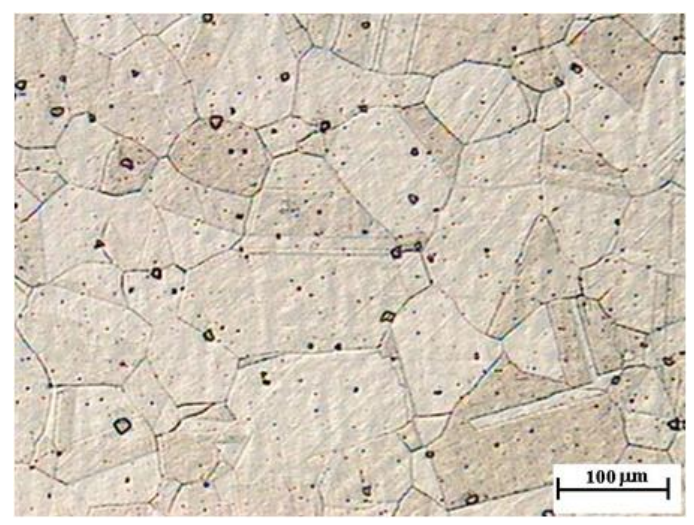

Figure 2. Optical micrograph of heat treated superalloy VAT 36. Magnification: $100 \times$. Heterogeneous grain sizes and small amount of precipitates. Small twinned areas are observed.

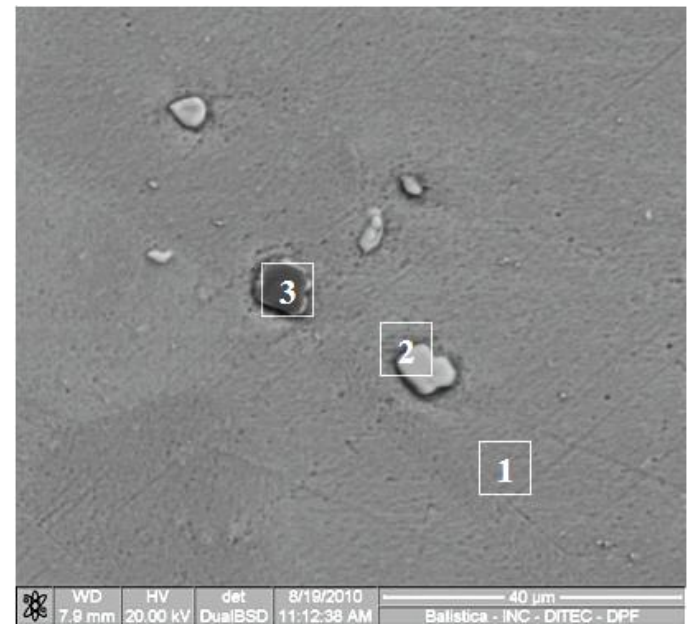

Figure 3. Scanning Electron Microscopy (SEM) micrograph of heat treated superalloy VAT 36 in backscattered electron image. Magnification: $3000 \times$. Matrix (1) and two different precipitates (2 and 3).

Matrix chemical composition (1) was already presented in Table 1 for this alloy. Precipitates highlighted (2 and 3 ) were evaluated via EDS with semi quantitative analysis depicted in Table 2.

Table 2. Semi quantitative analysis of precipitates 2 and 3 of VAT 36, showed in Figure 3.

\begin{tabular}{ccc}
\hline & \multicolumn{2}{c}{ ZAF-Method Standardless Quantitative Analysis } \\
\hline Element & Mass. \% (Precipitate 2) & Mass. \% (Precipitate 3) \\
\hline C K & 8.66 & 5.67 \\
Fe K & 2.28 & 4.65 \\
Ti K & 21.72 & 44.41 \\
Nb K & 67.24 & 18.69 \\
Cr K & 0.04 & 23.22 \\
Ni K & 0.06 & 3.36 \\
TOTAL & 100 & 100 \\
\hline
\end{tabular}

From the values observed in Table 2 we can infer a possible formation of $(\mathrm{Nb}, \mathrm{Ti}) \mathrm{C}$ carbides in precipitate 2 and $(\mathrm{Nb}, \mathrm{Ti}, \mathrm{Cr})$ carbides in precipitate 3. 


\subsubsection{Microstructural Evaluation of Superalloy VAT 32}

Figures 4 and 5 depict microstructures for VAT 32 alloy. Precipitates were observed distributed throughout the microstructures, with higher amount of these precipitates for VAT 32 alloy (Figure 4) when compared with VAT 36 (Figure 2).

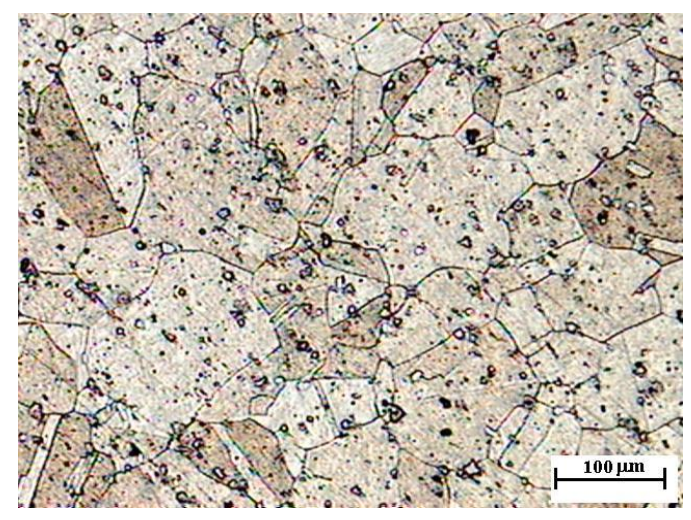

Figure 4. Optical micrograph of heat treated superalloy VAT 32. Magnification: $100 \times$. Higher amount of precipitates is observed, in comparison with VAT 36 microstructure. Negligible twinned areas are observed.

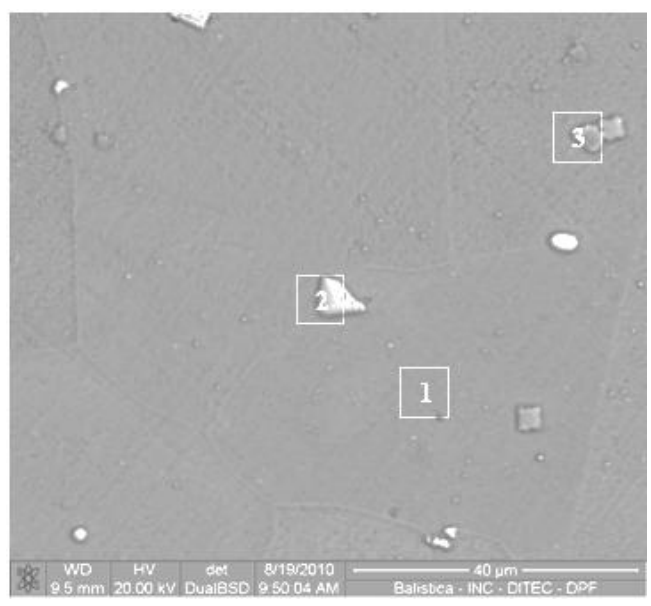

Figure 5. SEM micrograph of heat treated superalloy VAT 32 in backscattered electron mode in which matrix (1) and precipitates (2 and 3) are highlighted. Magnification: $3000 \times$.

Matrix chemical composition of VAT 32 (1) is available in Table 1 for this alloy. Precipitates highlighted (2 and 3) were evaluated via EDS with compositions depicted in Table 3 as follows.

Table 3. Semi quantitative analysis of precipitates 2 and 3 observed in VAT 32, highlighted in Figure 5.

\begin{tabular}{ccc}
\hline & ZAF-Method Standardless Quantitative Analysis \\
\hline Element & Mass \% (Precipitate 2) & Mass \% (Precipitate 3) \\
\hline C K & 5.23 & 2.23 \\
Fe K & 2.64 & 1.78 \\
Ti K & 23.51 & 31.30 \\
Nb K & 65.34 & 62.39 \\
Cr K & 1.32 & 1.34 \\
Ni K & 1.96 & 0.96 \\
Total & 100 & 100 \\
\hline
\end{tabular}

Both precipitates are quite similar for this alloy, possibly $(\mathrm{Nb}, \mathrm{Ti}) \mathrm{C}$ carbides. 
The chemical analysis of both alloys VAT 36 and VAT 32 (Table 1) showed high mass percentage of iron, nickel, and chromium, as expected for Fe-Ni-Cr based superalloys. Other elements such as carbon, aluminum, titanium, and niobium are also present, however at lower concentrations. These elements form carbides and intermetallic compounds and, as a result, cause the alloy precipitation hardening as described in [15]. Evaluation of EDS semi quantitative analysis, obtained from precipitates observed in Figures 3 and 5 showed considerably higher concentration of niobium and titanium at precipitates for VAT 32 alloy, indicative of $(\mathrm{Nb}, \mathrm{Ti}) \mathrm{C}$ carbides formation and possibly intermetallic $\mathrm{L1}_{2}$. For VAT 36, EDS analysis showed possibly formation of $(\mathrm{Nb}, \mathrm{Ti}, \mathrm{Cr})$ carbides at precipitate 3 . The weight percentage of precipitates is about $1.2 \%$ to VAT 36 and $5.5 \%$ to the VAT 32 , as calculated in GSAS software in Rietveld refinement. The largest amount of precipitates for the alloy VAT 32 is due to higher concentration of carbon, titanium, and niobium in its chemical composition.

\subsection{Rietveld Refinement}

The peaks of the intermetallic $\mathrm{L1}_{2}$ phases $\left[\mathrm{Ni}_{3} \mathrm{Al}, \mathrm{Ni}_{3}\left(\mathrm{Al}_{0.5} \mathrm{Ti}_{0.5}\right)\right]$ are superimposed with the highest peak of $\gamma$ austenitic matrix. A refinement of the crystal structure was accomplished by the Rietveld method (Figures 6 and 7), due to the difficulty of distinguishing the phase $\gamma$ and other precipitates with similar lattice parameters as described in $[16,17]$. Table 4 contains the lattice parameters and calculated weight percentages of the phases for the alloys VAT 36 and VAT 32.

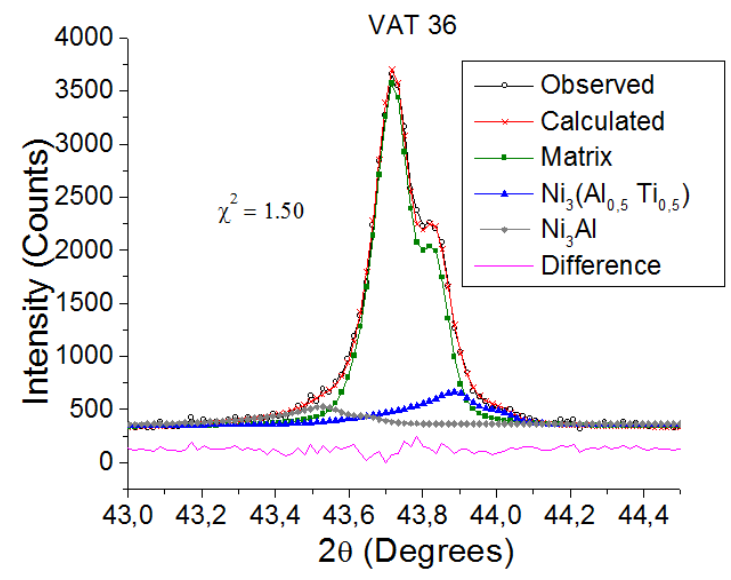

Figure 6. Rietveld refinement carried out at $2 \theta=44^{\circ}$ for the alloy VAT 36 .

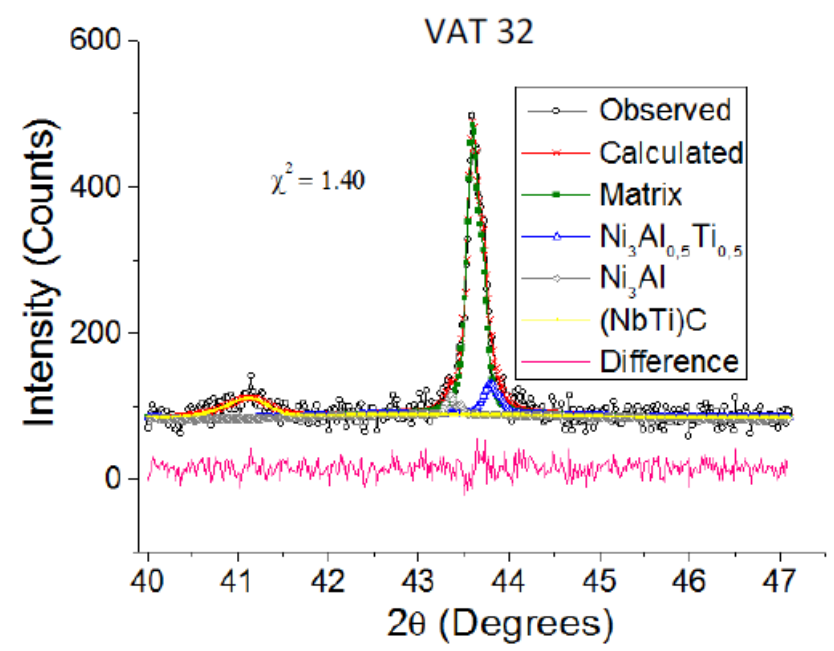

Figure 7. Rietveld refinement carried out in $40^{\circ} \leq 2 \theta \leq 47^{\circ}$ (VAT 32). 
Table 4. Lattice parameters and percentages of the phases for the alloys VAT 36 and VAT 32.

\begin{tabular}{|c|c|c|}
\hline \multicolumn{3}{|c|}{ VAT 36} \\
\hline Phases & wt. $\%$ Calculated & Lattice Parameters (̊̊) \\
\hline Matrix $(\gamma)$ & 92 & $a=b=c=3.581$ \\
\hline $\mathrm{L}_{2}$ Phase & 5 & $a=b=c=3.596$ \\
\hline $\mathrm{L}_{2}$ Phase & 3 & $a=b=c=3.568$ \\
\hline \multicolumn{3}{|c|}{ VAT 32} \\
\hline Phases & wt. $\%$ Calculated & Lattice Parameters (Å) \\
\hline $\operatorname{Matrix}(\gamma)$ & 64 & $a=b=c=3.590$ \\
\hline $\mathrm{L}_{2}$ Phase & 9 & $a=b=c=3.611$ \\
\hline $\mathrm{L}_{2}$ Phase & 5 & $a=b=c=3.581$ \\
\hline$(\mathrm{NbTi}) \mathrm{C}$ & 22 & $a=b=c=4.384$ \\
\hline
\end{tabular}

\subsection{Creep Tests}

Figures 8-10 show the creep curves corresponding to deformation $\varepsilon$ as a function of the time $t$ for VAT 36 and VAT 32 alloys in creep tests carried out for a temperature range of $675-750{ }^{\circ} \mathrm{C}$ and stress range of 500-600 $\mathrm{MPa}$.

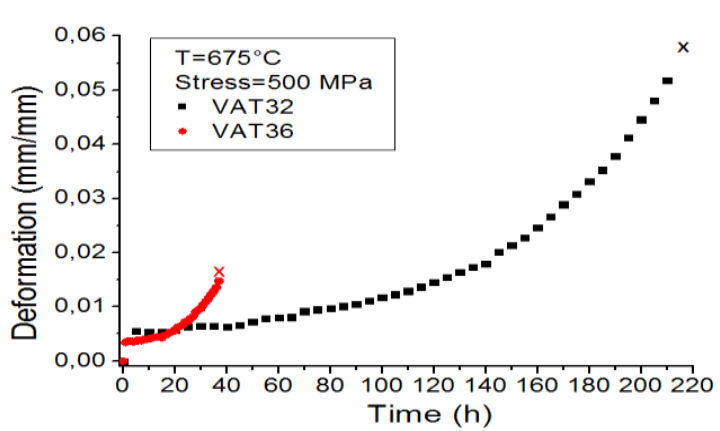

(a)

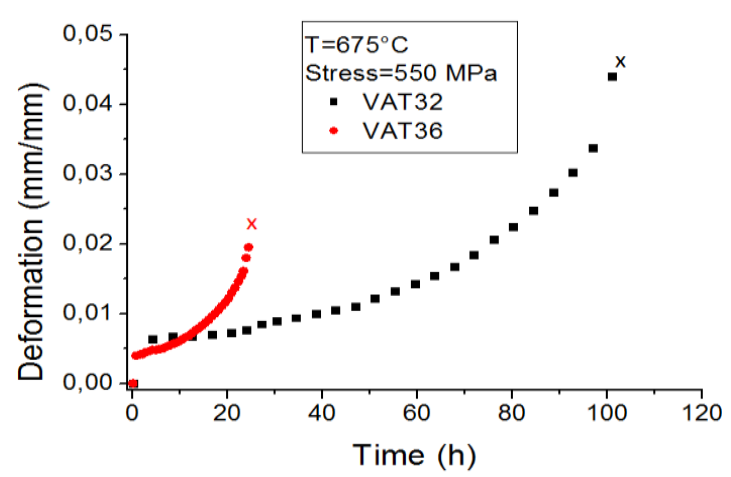

(b)

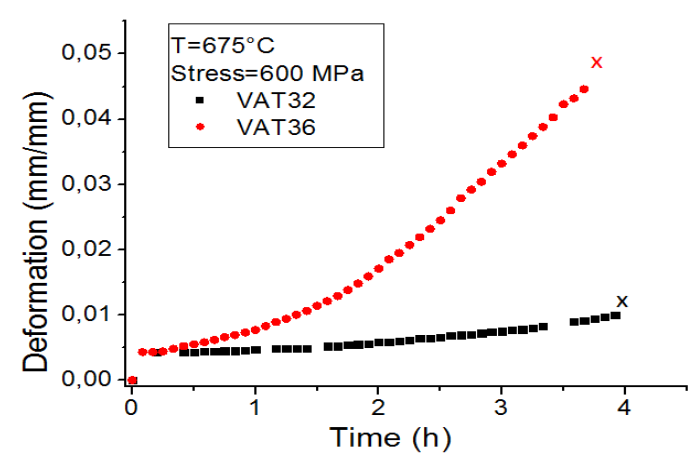

(c)

Figure 8. Creep curves of the alloy VAT 36 and VAT 32 at $675^{\circ} \mathrm{C}$ at the stress of (a) 500 . (b) 550 and (c) $600 \mathrm{MPa}$. 


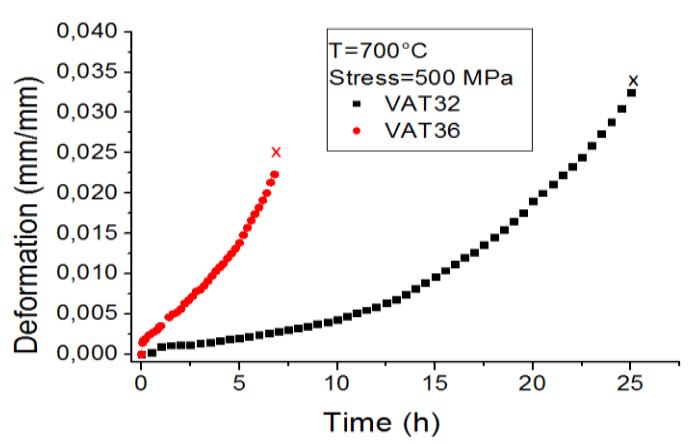

(a)

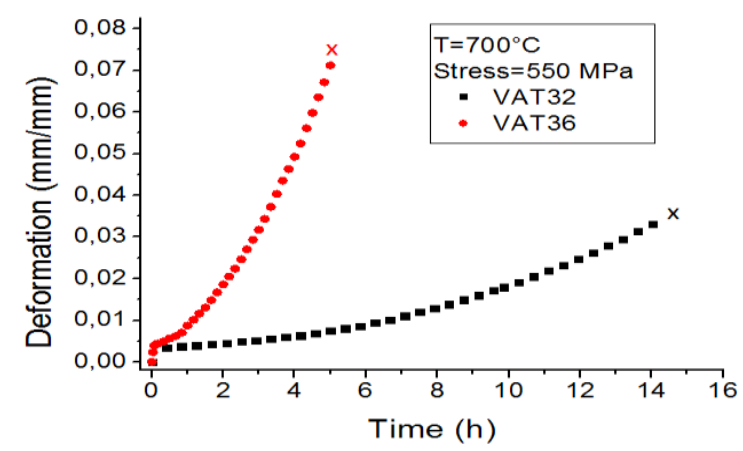

(b)

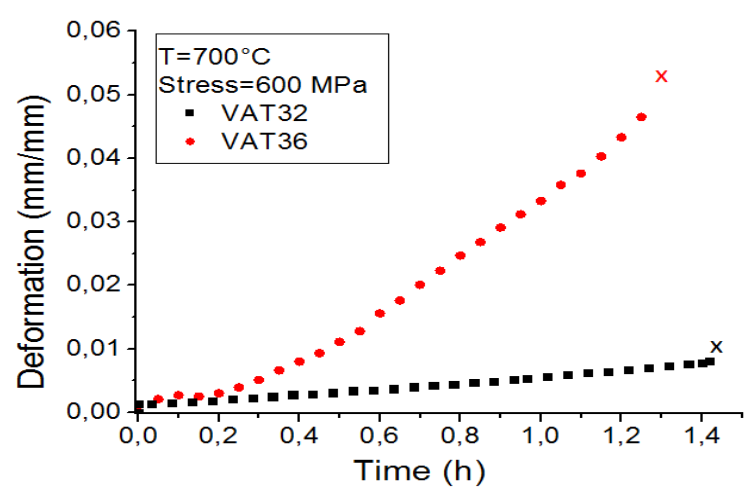

(c)

Figure 9. Creep curves of the alloys VAT 36 and VAT 32 at $700{ }^{\circ} \mathrm{C}$ at the stress of: (a) 500 . (b) 550 and (c) $600 \mathrm{MPa}$.

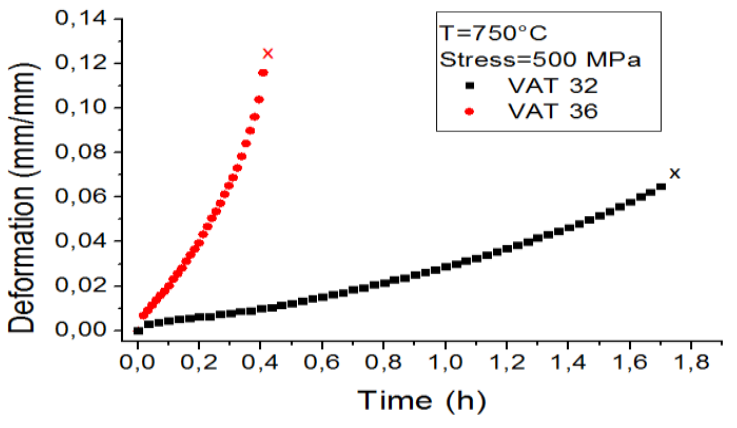

(a)

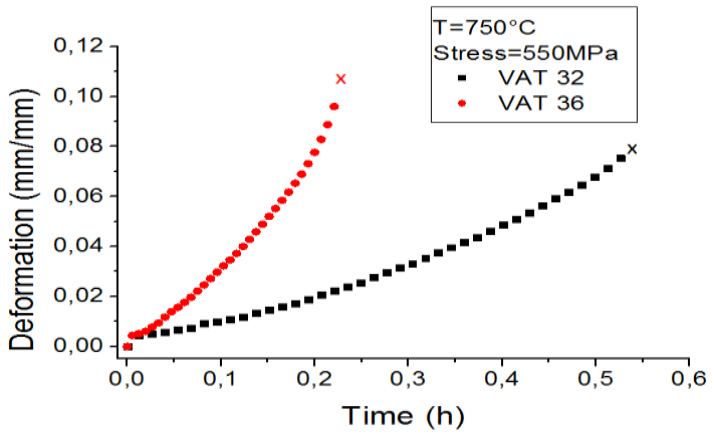

(b)

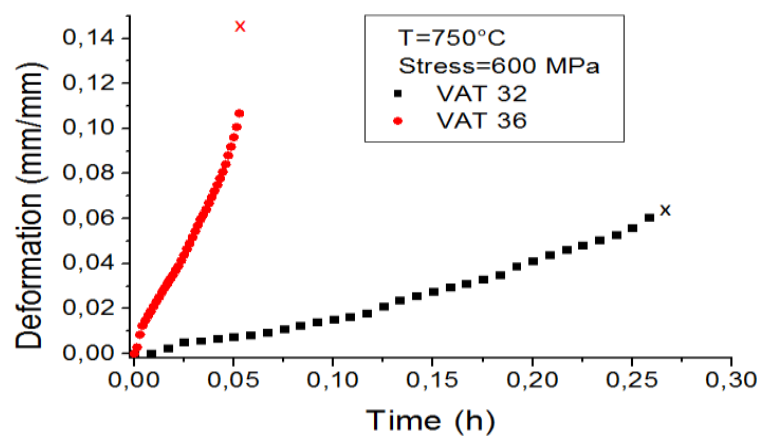

(c)

Figure 10. Creep curves of the alloys VAT 36 and VAT 32 the $750{ }^{\circ} \mathrm{C}$ at the stress of: (a) 500 . (b) 550 and (c) $600 \mathrm{MPa}$. 
Table 5 shows the creep data of all the creep curves.

Table 5. Creep tests data of the alloys VAT 36 and VAT 32 at temperatures $(T)$ of 675,700 , and $750{ }^{\circ} \mathrm{C}$ and stresses $(\sigma)$ of 500,550 , and $600 \mathrm{MPa}$, showing creep rate $\left(\dot{\varepsilon_{S}}\right)$, time of failure $\left(t_{\mathrm{f}}\right)$ and reduction of area (RA).

\begin{tabular}{|c|c|c|c|c|c|}
\hline $\mathrm{T}\left({ }^{\circ} \mathrm{C}\right)$ & Material & $\sigma(\mathrm{MPa})$ & $\dot{\varepsilon_{s}}(1 / h)$ & $t_{\mathrm{f}}(\mathrm{h})$ & RA (\%) \\
\hline \multirow{7}{*}{675} & \multirow{4}{*}{ VAT 36} & 500 & $3.25 \times 10^{-4}$ & 37.25 & 3.31 \\
\hline & & 550 & $9.08 \times 10^{-4}$ & 25.27 & 3.30 \\
\hline & & 600 & $4.01 \times 10^{-3}$ & 3.76 & 5.91 \\
\hline & & 500 & $5.08 \times 10^{-5}$ & 214.58 & 3.30 \\
\hline & \multirow[t]{3}{*}{ VAT 32} & 550 & $1.75 \times 10^{-4}$ & 102.33 & 2.00 \\
\hline & & 600 & $7.56 \times 10^{-4}$ & 3.96 & 1.32 \\
\hline & & 500 & $2.36 \times 10^{-3}$ & 6.95 & 14.12 \\
\hline \multirow{5}{*}{700} & \multirow[t]{3}{*}{ VAT 36} & 550 & $7.89 \times 10^{-3}$ & 5.12 & 11.64 \\
\hline & & 600 & $2.58 \times 10^{-2}$ & 1.30 & 12.26 \\
\hline & & 500 & $4.4 \times 10^{-4}$ & 25.16 & 4.61 \\
\hline & \multirow[t]{3}{*}{ VAT 32} & 550 & $1.55 \times 10^{-3}$ & 14.57 & 3.96 \\
\hline & & 600 & $5.93 \times 10^{-3}$ & 1.43 & 3.26 \\
\hline \multirow{6}{*}{750} & & 500 & $1.71 \times 10^{-1}$ & 0.41 & 19.29 \\
\hline & \multirow[t]{3}{*}{ VAT 36} & 550 & $3.87 \times 10^{-1}$ & 0.23 & 16.45 \\
\hline & & 600 & $14.65 \times 10^{-1}$ & 0.054 & 17.40 \\
\hline & & 500 & $2.15 \times 10^{-2}$ & 1.73 & 5.91 \\
\hline & \multirow[t]{2}{*}{ VAT 32} & 550 & $8.43 \times 10^{-2}$ & 0.53 & 5.26 \\
\hline & & 600 & $2.38 \times 10^{-1}$ & 0.26 & 4.61 \\
\hline
\end{tabular}

Table 5 shows smaller reduction of area after creep tests for VAT 32 alloy. Therefore this alloy has lower ductility than the VAT 36. The creep rate is also lower for VAT 32 for all temperatures and stresses by, at least, one order of magnitude. This higher creep resistance for this alloy (VAT 32) is attributed to a larger amount of MC carbides and intermetallic compound $\mathrm{L}_{2}$. The VAT 32 showed also higher times to failure at lower stresses.

At $675{ }^{\circ} \mathrm{C}$, when the stress is increased from 500 to $600 \mathrm{MPa}$, the time to rupture decreases 54.2 times for the VAT 32 and to 9.9 times for the VAT 36. At $700{ }^{\circ} \mathrm{C}$, this reduction is of 17.6 times for the VAT 32 and 5.3 times for the VAT 36. At a temperature of $750{ }^{\circ} \mathrm{C}, t_{\mathrm{f}}$ decreases 6.6 times for the VAT 32 and 7.6 times for the VAT 36. Increase of creep tests temperatures results in higher ductility and the material becomes less sensitive to stress, causing lower differences between the times of rupture for higher stresses for both compositions. In general, both alloys showed typical behavior in creep tests, with decrease in the creep rate and increase of the rupture time with reduction of the stress or temperature. This indicates that the alloys exhibits creep rate sensitivity to both temperature and applied stress. For metals and alloys, the greater the temperature and higher strain rate, the earlier the stage of cavities and cracks formation will be [18].

The higher creep resistance of the alloy VAT 32 in comparison to VAT 36 is caused by the largest fraction of carbides $(\mathrm{Nb}, \mathrm{Ti}) \mathrm{C}$ and intermetallic $\mathrm{L}_{2}$ in VAT 32 alloys. These precipitates originated from the higher amount of carbon, titanium, and niobium in the VAT 32 chemical composition. These precipitates are stable and have a low rate of coalescence. As a result dislocations sliding are hindered by these obstacles during creep deformation [19]. Carbides also produce an anchoring effect at grain boundaries, hence delaying relative sliding between grains, affecting the ease with which vacancies can be generated in these regions $[20,21]$. Dependence of the steady state creep rate with stress and temperature could be expressed as an Arrhenius type relationship, and represented by the Equation (1) [21].

$$
\dot{\varepsilon_{s}}=B_{0} \sigma^{n} \exp \left(\frac{-Q_{\mathrm{C}}}{R T}\right)
$$


where $B_{0}$ is a factor dependent on the stress and the structure of the material, $\sigma$ is the stress applied, $R$ is the gas constant, and $T$ is the absolute temperature. The concept of a mechanism responsible for creep phenomenon can be characterized by different values of stress exponent $n$ combined with the activation energy $Q_{c}$. Therefore, values of $n$ and $Q_{c}$ were determined in this work, based on Equation (1) and the data in Table 3, as can be seen in Figures 11 and 12.

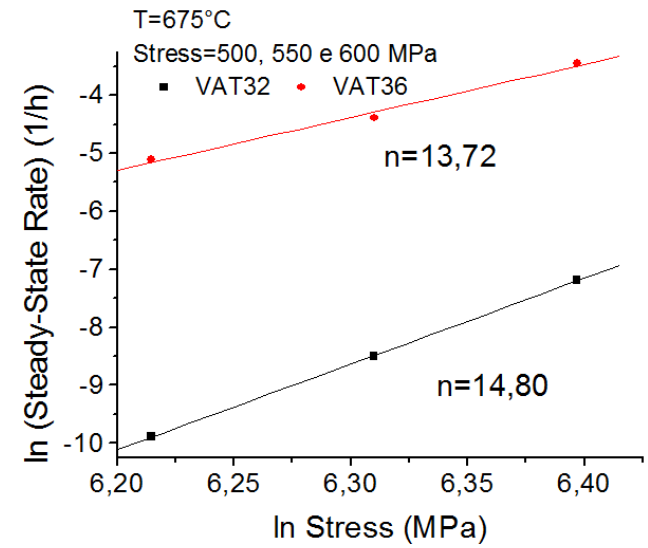

(a)

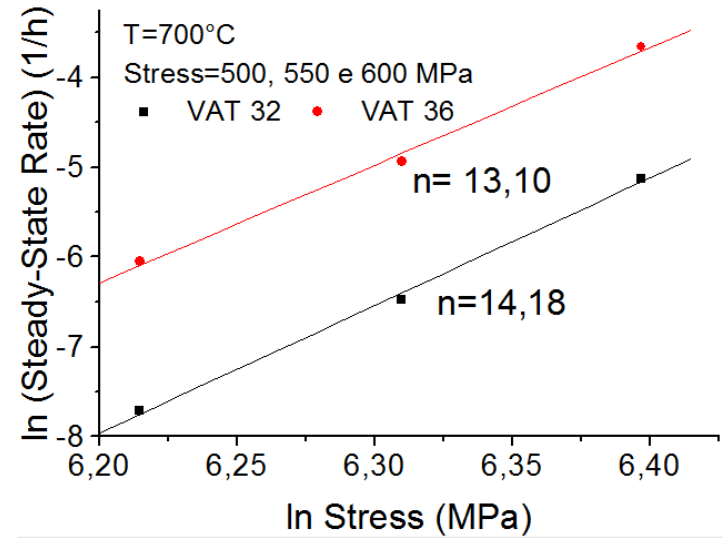

(b)

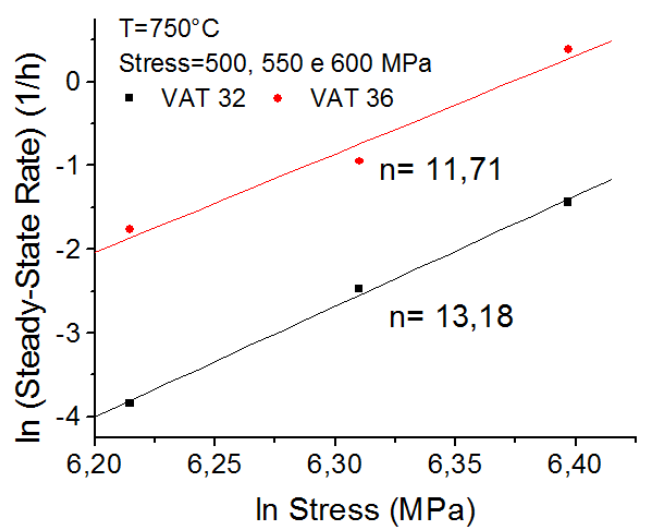

(c)

Figure 11. Dependence of the steady-state creep rate with the applied stress to the alloys VAT 32 and VAT 36 at: (a) $675^{\circ} \mathrm{C}$. (b) $700{ }^{\circ} \mathrm{C}$ and (c) $750{ }^{\circ} \mathrm{C}$.

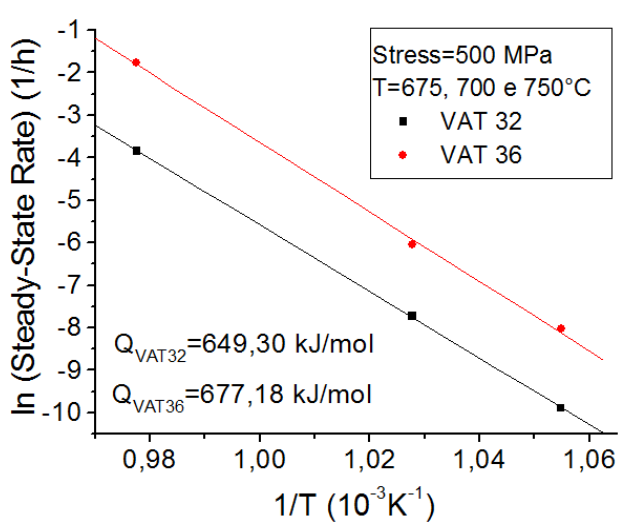

(a)

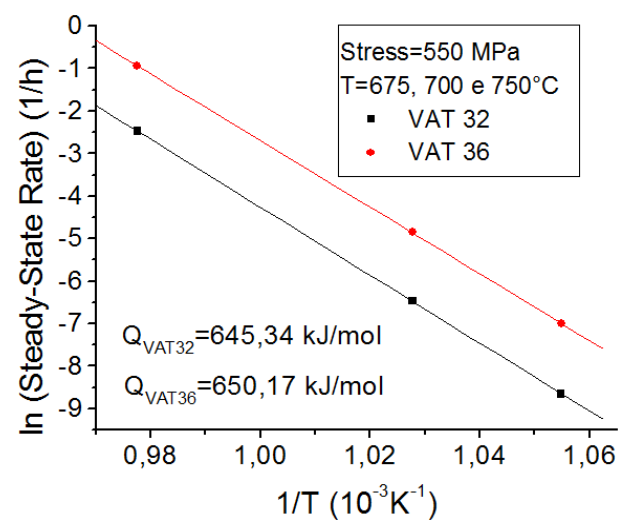

(b)

Figure 12. Cont. 


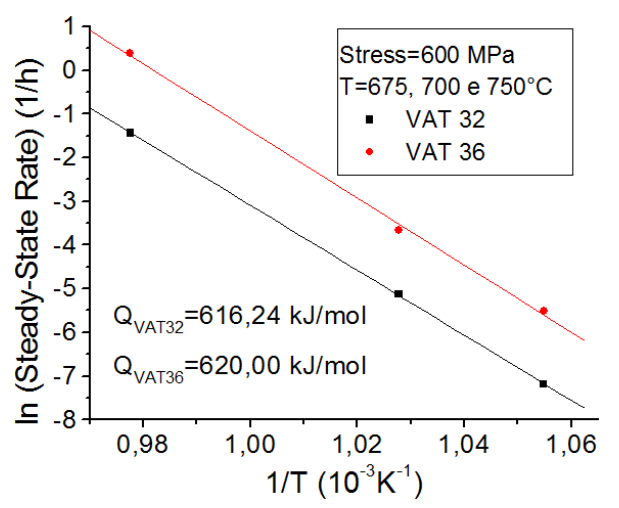

(c)

Figure 12. Steady-state creep rate dependence with the temperature for the alloys VAT 32 and VAT 36 at: (a) $500 \mathrm{MPa}$. (b) $550 \mathrm{MPa}$ and (c) $600 \mathrm{MPa}$.

At $675{ }^{\circ} \mathrm{C}$ a stress exponent of 14.80 was obtained for the VAT 32 and 13.72 for the VAT 36. At $700{ }^{\circ} \mathrm{C}, n$ values reached 14.18 for the VAT 32 and 13.10 for the VAT 36 . At $750{ }^{\circ} \mathrm{C}$ the stress exponents were 13.18 for the VAT 32 and 11.71 for the VAT 36.

Activation energies values at $600 \mathrm{MPa}$ were near $616 \mathrm{~kJ} / \mathrm{mol}$ for the VAT 32 and $620 \mathrm{~kJ} / \mathrm{mol}$ for the VAT 36. At $550 \mathrm{MPa}$ these values reached $645 \mathrm{~kJ} / \mathrm{mol}$ for the VAT 32 and $650 \mathrm{~kJ} / \mathrm{mol}$ for the VAT 36. At $500 \mathrm{MPa}$ activation energies were $649.30 \mathrm{~kJ} / \mathrm{mol}$ for the VAT 32 to $677 \mathrm{~kJ} / \mathrm{mol}$ for the VAT 36.

The occurrence of a given creep mechanism depends on the test conditions. For lower stresses and high temperatures, possibly dislocation climb over carbides and precipitates would prevail. For higher stresses and lower temperatures shear mechanisms involving stacking fault occurs over a wide range of experimental conditions [22,23]. Previous research showed the dependence of velocity of dislocation movement with carbides volumetric fraction [24,25].

Dislocations movement is hindered by carbide particles. Reduced creep rate of VAT 32 is strongly affected by higher amounts of carbides $(\mathrm{Nb}, \mathrm{Ti}) \mathrm{C}$ and intermetallic $\mathrm{L1} 1_{2}$, when compared to VAT 36. Those particles behave as obstacles to dislocations movement, with the creep rate dependent on their size and distribution.

\subsection{Failure Analysis}

Fracture surfaces of crept samples are depicted in fractrographs showed in Figures 13-15. Figure 13 shows the fractured surface of sample VAT 36 after creep test. The crack starts with intergranular mode (region A). After reaching critical size, crack propagation occurs at transgranular ductile mode (region B), with dimples.

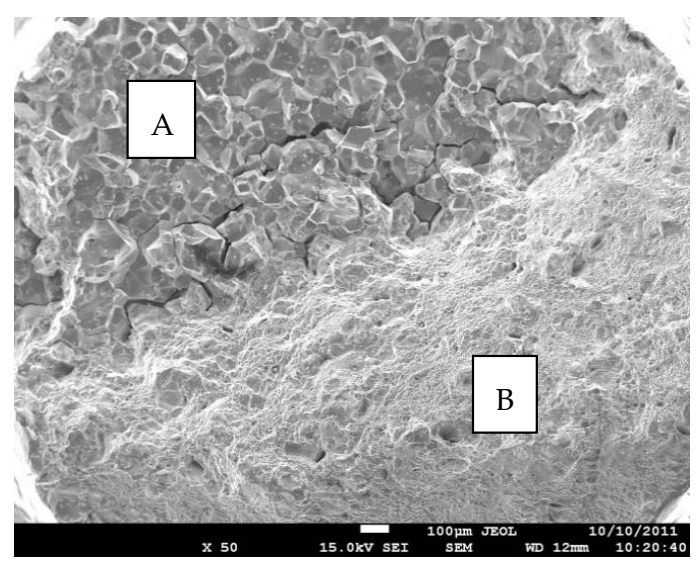

Figure 13. Fracture surface of crept VAT 36 sample, in creep test at $700{ }^{\circ} \mathrm{C}$ and stress of $600 \mathrm{MPa}$, with intergranular (A) and transgranular ductile (B) regions. 


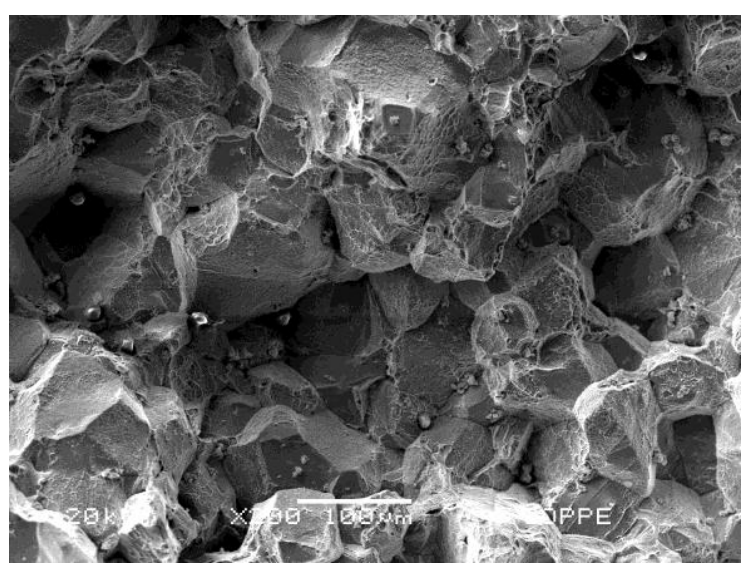

(a)

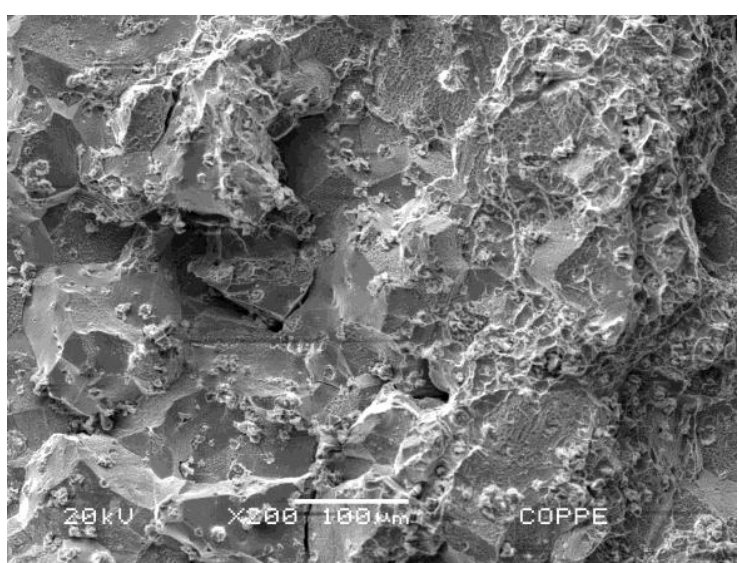

(b)

Figure 14. Surface of fracture initiation sites of VAT 36 (a) and VAT $32(\mathbf{b})$, crept at $700{ }^{\circ} \mathrm{C}$ and $500 \mathrm{MPa}$, with an intergranular mode for both cases. Considerable amount of precipitated carbides can be seen at the VAT 32 surface.

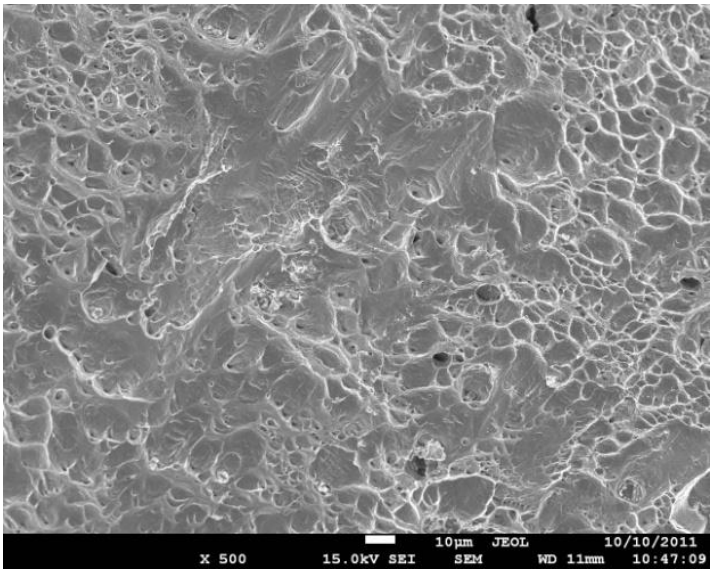

(a)

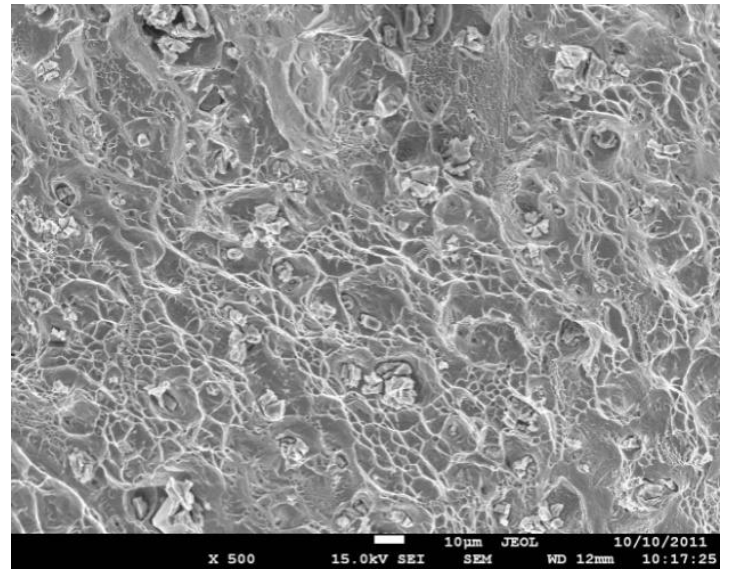

(b)

Figure 15. Final portions of fractured surfaces of VAT 36 (a) and VAT 32 (b) alloys, subjected to creep tests at $750{ }^{\circ} \mathrm{C}$ showing dimples of ductile fracture.

Detailed examination of the crack initiation of both compositions showed intergranular mode at these regions, as depicted in Figure 14. Higher amount of precipitated carbides can be observed for VAT 32 composition.

At the final region of fractured surfaces, ductile fractures prevailed, with a large amount of dimples. Particulate carbides remained inside dimples for VAT 32 alloy, as depicted in Figure 15b.

The fractrographs showed intergranular fracture at creep initial stages for both alloys. Steps of creep intergranular fracture are nucleation, growth, and subsequent binding of voids at triple points. The formation of cavities is controlled by diffusion processes. The stacking of dislocations in regions near the grain boundaries during creep can increase the stress concentration favoring the initiation and propagation of intergranular microcracks [22].

At the final surface cracks, ductile fracture prevails (transgranular ductile fracture) with formation and coalescence of microcavities of variable shapes and sizes. The size and shape of the dimples are governed by the number and distribution of nucleated microcavities and by the level of internal stresses present in the material [26].

The alloy VAT 36 showed more areas of transgranular ductile fracture, considering its higher ductility caused by lower weight percentage of carbides and intermetallics. 


\section{Conclusions}

1. Rietveld refinement allowed qualitative and quantitative evaluation of carbides and intermetallic precipitates in both alloys. The VAT 36 has approximately $8 \mathrm{wt} . \%$ of intermetallic $\mathrm{L}_{2}$ and VAT 32, $14 \mathrm{wt} . \%$. The precipitates hindered dislocation slip and grain boundaries slip, mainly in VAT 32 alloy, increasing its creep resistance.

2. The VAT 32 alloy showed smaller reduction in area after creep tests in relation to VAT 36 . This result is caused by lower ductility of VAT 32 originated from higher mass percentage of carbon in its composition, favoring formation of phases based on carbides.

3. The higher creep resistance of the alloy VAT 32 is related to its substantial fraction of carbides $(\mathrm{Nb}, \mathrm{Ti}) \mathrm{C}$ and intermetallic $\mathrm{L}_{2}$, provided by its larger carbon content. The excess of titanium and niobium unreacted with carbon combines with nickel giving rise to intermetallic phases $\mathrm{L1}_{2}$. These precipitates are stable and have low rate of coalescence. As a result, during creep deformation these precipitates produce anchoring effect of grain boundaries hindering relative slide between grains and therefore causes crack formation delay. These volume defects act also as obstacles to dislocation slip and climb, decreasing the creep rate.

4. Failure analysis of surface fractures of crept samples showed intergranular failure mechanism at crack origin for both alloys VAT 36 and VAT 32. Intergranular fracture involves nucleation, growth, and subsequent binding of voids. The final fractured portion showed transgranular ductile failure, with dimples of different shapes and sizes, typical of ductile failure. Transgranular ductile fracture involves the formation and coalescence of microcavities with dissimilar shape and sizes. The VAT 32 showed smaller areas of intragranular failure mechanism (dimples). This behavior is caused by its lower ductility.

5. Stress exponents obtained is this work were in a range of $14.80-11.71$ and activations energies between $677-616 \mathrm{~kJ} / \mathrm{mol}$. The occurrence of a given creep mechanism depends on the test conditions. At creep tests of VAT 32 and VAT 36, for lower stresses and high temperatures, dislocation climb over carbides and precipitates possibly prevail. For higher stresses and intermediate temperatures shear mechanisms involving stacking fault can occur over a wide range of experimental conditions

Author Contributions: Conceptualization: C.R.M.d.S., V.J.G., S.J.G., D.A.P.R., J.L.d.A.F., J.A.A.; Validation: C.R.M.S., V.J.G., S.J.G., D.A.P.R., J.L.d.A.F., J.A.A.; Formal Analysis: C.R.M.d.S., V.J.G; Investigation: C.R.M.d.S., D.A.P.R., V.J.G; Writing-Review and Editing: C.R.M.d.S., V.J.G.; Supervision: C.R.M.d.S.

Funding: This research received no external funding.

Acknowledgments: We would like to show our gratitude to Villares Metals who provided the samples for creep tests.

Conflicts of Interest: The authors declare no conflict of interest.

\section{References}

1. Sawada, K.; Kimura, K.; Abe, F. Mechanical response of $9 \% \mathrm{Cr}$ heat-resistant martensitic steels to abrupt stress loading at high temperature. Adv. Mater. Sci. Eng. A 2003, 358, 52-58. [CrossRef]

2. Furtado, H.C.; de Almeida, L.H.; Le May, I. Precipitation in 9Cr-1Mo steel after creep deformation. Mater. Charact. 2007, 58, 72-77. [CrossRef]

3. Ennis, P.J.; Quadakkers, W.J. 9-12\% Chromium Steels: Application Limit and Potential for Further Development in Parsons. Advanced Materials for 21st Century Turbines and Power Plants; The Institute of Materials: London, UK, 2000; pp. 265-275.

4. Berneti, J.; Brada, B.; Kosec, G.; Bricelj, E.; Kosec, B.; Vodopivec, F.; Kosec, L. Centreline Formation of Nb(C, N) eutectic in structural steel. Metall 2010, 49, 29-32.

5. Schafrik, R.E.; Ward, D.D.; Groh, J.R. Application of alloy 718 in GE aircraft engines: Past, present and next five years. Superalloys 2001, 718, 1-11. 
6. Schafrik, R.; Christodoulou, L.; Williams, J.C. Collaboration isan essential part of materials development. JOM 2005, 57, 14-16. [CrossRef]

7. Hohmann, M.; Brooks, G.; Spiegelhaue, C. production methods and applications for high-quality metal powders and sprayformed products. Acta Metall. Sin. (Eng. Lett.) 2005, 18, 15-23.

8. Walston, S.; Cetel, A.; MacKay, R.; O'Hara, K.; Duhl, D.; Dreshfield, R. Joint development of a fourth generation single crystal superalloy. Superalloys 2004, 15-24.

9. Clarke, D.; Bold, S. Materials Developments in aeroengine gas turbines. In Aerospace Materials; Institute of Physics Publishing: Bristol, UK, 2001; pp. 71-80.

10. Smith, G.D.; Patel, S.J. The role of niobium in wrought precipitation-hardened nickel-base alloys. Superalloys 2005, 718, 625-706.

11. Tresa, M.P.; Sammy, T. Nickel-based superalloys for advanced turbine engines: Chemistry, microstructure and properties. J. Propul. Power. 2006, 22, 361-374.

12. Edmonds, D.V.; Cochrane, R.C. The effect of alloying on the resistance of carbon steel for oilfield applications to $\mathrm{CO}_{2}$ corrosion. Mat. Res. 2005, 8, 377-385. [CrossRef]

13. American Society for Testing and Materials (ASTM). ASTM E139-11: Standard Test Methods for Conducting Creep, Creep Rupture, and Stress Rupture Tests of Metallic Materials; ASTM International: West Conshohocken, PA, USA, 2011.

14. Almeida, G.F.C.; Couto, A.A; Reis, D.A.P.; Massi, M.; Sobrinho, A.S.S.; Lima, N.B. Effect of plasma nitriding on the creep and tensile properties of the Ti-6Al-4V alloy. Metals 2018, 8, 618. [CrossRef]

15. Donachie, M.J; Donachie, S.J. Superalloys: A Technical Guide, 2nd ed.; ASM International: Materials Park, $\mathrm{OH}$, USA, 2002.

16. Xu, Y.; Jin, O.; Xiao, X.; Cao, X.; Jia, G.; Zhu, Y.; Yin, H. Strengthening mechanisms of carbon in modified nickel-based superalloy Nimonic 80A. Mater. Sci. Eng. A 2011, 528, 4600-4607. [CrossRef]

17. Tian, S.; Wang, M.; Yu, H.; Yu, X.; Li, T.; Qian, B. Influence of element Re on lattice misfits and stress rupture properties of single crystal nickel-based superalloys. Mater. Sci. Eng. A 2010, 527, 4458-4465.

18. Kassner, M.E. Fundamentals of Creep in Metals and Alloys, 3rd ed.; Elsevier Ltd.: Amsterdam, The Netherlands, 2015.

19. He, L.Z.; Zheng, Q.; Sun, X.F.; Guan, H.R.; Hu, Z.Q.; Tieu, A.K.; Lu, C.; Zhu, H.T. Effect of carbides on the creep properties of a Ni-base superalloy M963. Mater. Sci. Eng. A 2005, 397, 297-304. [CrossRef]

20. Ha, V.T.; Jung, W.S. Effects of heat treatment processes on microstructure and creep properties of a high nitrogen 15Cr-15Ni austenitic heat resistant stainless steel. Mater. Sci. Eng. A 2011, 528, 7115-7123. [CrossRef]

21. Evans, R.W.; Wilshire, B. Introduction to Creep; The Institute of Materials: London, UK, 1993; p. 115.

22. Tian, S.; Xie, J.; Zhou, X.; Qian, B.; Lun, J.; Yu, L.; Wang, W. Microstructure and creep behavior of FGH95 nickel-base superalloy. Mater. Sci. Eng. A 2011, 528, 2076-2084.

23. Sajjadi, S.A.; Nategh, S.A. High temperature deformation mechanism map for the high performance Ni-base superalloy GTD-111. Mater. Sci. Eng. A 2001, 307, 158-164. [CrossRef]

24. Society of Automotive Engineers. SAE J775: Engine Poppet Valve Information Report; SAE International: Warrendale, PA, USA, 2004.

25. American Society for Testing and Materials Standards. ASTM B637: Standard Specification for Precipitation-Hardening Nickel Alloy Bars, Forgings and Forging Stock for High Temperature Service. ASTM: West Conshohocken, PA, USA, 2011.

26. Brooks, C.R.; Choudhury, A. Fracture mechanisms and microfractographic features. In Metallurgical Failure Analysis; McGraw-Hill: New York, NY, USA, 1993; pp. 119-211.

(C) 2018 by the authors. Licensee MDPI, Basel, Switzerland. This article is an open access article distributed under the terms and conditions of the Creative Commons Attribution (CC BY) license (http://creativecommons.org/licenses/by/4.0/). 